\title{
Can There Be Post-Persons and What Can We Learn From Considering Their Possibility? ${ }^{1}$
}

\author{
Ivars Neiders (Rīga Stradiṇš University)
}

\section{Introduction}

Different perspectives of enhancing humans have raised different kinds of issues, but one of the most prominent is the possible radical increase of the gap between enhanced and unenhanced persons. For example Geroge Annas has claimed that if we were to succeed in our attempts to create perfect humans this would create deadly consequences:

since the ««improved» posthumans would inevitably come to view the «naturals» as inferior, as a subspecies of humans suitable for exploitation, slavery, or even extermination. Ultimately, it is this prospect of what can be termed "genetic genocide» that makes cloning combined with genetic engineering a potential weapon of mass destruction, and the biologist who would attempt it a potential bioterrorist (Annas 2002) ${ }^{2}$.

The issue is not new and has been raised in different forms not just in bioethical literature, but in popular culture as well, from Huxley's Brave New World to Andrew Niccol's 1997 movie Gattaca. However, what is at stake here is not always clear. One may suppose that the basic perceived threat created by enhancing humans is creating beings that would surpass mere humans in different ways, by having more advanced capacities to reason and remember, by being physically more developed, by having considerably longer life-span, etc. And it is not that unreasonable to think that beings with such abilities we might create a society that is considerably more unequal than the one we live in now. Pessimists (such as Annas in the quoted passage) say that this is "inevitable". The more optimistically-minded would admit that there are risks, but that they can be avoided, provided certain policies and controls are in place. After all, we are well aware of differences between people in our current society-some of us are smarter than others, some are more physically developed than the majority, etc.-but these differences, all other things being equal, cannot justify unequal treatment. There is an assumption that, morally speaking, everybody is equal whatever intellectual, physical,

1 The publication of the paper in this volume is a part of a project funded by the Polish National Science Centre (Dec-2013/10/E/HS5/00157).

2 See also Fukuyama 2002, 9-10. 
racial or other differences there are. However, one may press the issue and raise the following question-"What if as a result of enhancement, there will emerge beings whose moral status would be higher than that of persons? Is there anything that rules out this possibility?" This, using Buchanan's words, is a "more profound worry", because it challenges the just mentioned assumption of moral equality (Buchanan 2011, 209)3.

This worrying possibility of creating post-persons (or-as some call them-«supra-persons») has recently drawn the attention of many respectable bioethicists (see: Buchanan 2009, McMahan, 2009, Savulescu, 2009, Agar 2013, Douglas 2013b) ${ }^{4}$. So far the main questions raised about post-persons have been the two following ones: first, is the possibility of the existence of post-persons conceivable at all, and second, if there is the possibility-however distant-to create such beings, would it be a good idea to have them around? Buchanan (2011), for example, argues that the idea of beings with moral status higher than that of persons is implausible. Agar $(2014)^{5}$, on the other hand, disagrees and proposes an argument to the conclusion that there might be post-persons; however, he argues that it would be morally wrong to create such beings. In what follows I am not going to discuss the second question at all and I shall not (directly at least) address the first one as well. Instead, I shall pursue the slightly different task of questioning some of the assumptions on which much of the recent literature on human cognitive enhancement relies. There are at least two issues with Agar's account. First, he dismisses the importance of phenomenology in framing our ethical outlook. Second, he seems to follow the assumption made by many utilitarian ethicists that certain features that account for our personhood have some universal relevance. My contention is that these assumptions should be reconsidered if we want to get a more realistic view of the phenomenon of cognitive enhancement.

I proceed in two steps. In the next section I discuss Agar's arguments for the possibility of post-persons. The main purpose of this is to introduce the conceptual framework used by the authors who address the issue and to illustrate the main conceptual obstacles when talking about post-persons. In the third section I try to make clear what I think is wrong with Agar's (and others') overall take on the issue of post-persons.

\footnotetext{
3 Buchanan calls it "Moral Equality Assumption", ibid.

${ }^{4}$ Journal of Medical Ethics (2013, Vol. 39) featured a discussion on the biomedical enhancement of moral status with Agar's (2013) paper as Feature Article and replies from Sparrow, Hauskeller, Wasserman, Persson, and Douglas.

${ }^{5}$ Agar 2014 Ch. 8 and 9 are more elaborated versions of Agar 2013. Further in my discussion I shall refer to the book.
} 


\section{Agar on Post-Persons}

Agar presents his position by engaging with Buchanan's arguments against the possibility of post-persons. Buchanan (2011), according to Agar $(2014,161)$ has identified three different obstacles that make the idea of post-persons implausible. First, there is (1) the problem of the logic of thresholds, second, (2) the problem of how to improve upon inviolability, and, third, (3) the problem of expressing moral statuses higher than personhood. I shall give a short sketch of each obstacle as presented by Buchanan, and show how Agar tries to overcome them. While doing that I shall make some comments on Agar's proposed solutions.

\subsection{The logic of thresholds}

Although the terms "moral status" and "moral standing" are used interchangeably, Buchanan distinguishes them. In his account a being has moral standing if "it counts morally, in its own right". "Moral standing" is not a comparative notion. The being either counts morally or not. In contrast to that "moral status" is a comparative notion as different beings may have different moral statuses, i.e., some may count more than others (Buchanan, 2011, 20910). According to Buchanan the moral status of persons is such that it rules out the possibility of having it in greater or lesser degree. Or, to put it in another words, the concept of moral status is a threshold and not a scalar concept. As Buchanan points out:

According to theories that accord moral status (or the highest moral status) to persons, understood as beings who have the capacity for practical rationality or for engaging in practices of mutual accountability, what matters is whether one has the capacity in question. Once the threshold is reached, how well one reasons practically or how well one engages in practices of mutual accountability does not affect moral status $(2011,215)$.

It follows from this account that as soon as a creature is a person, he or she has the same moral status as any other person whatever the differences there are between these persons with regard to the capacities that constitute their personhood. It is like having a driver's licence-as soon as you get one, you have the same rights as any other licence owner whether or not they are worse or better drivers than you. Thus, as soon as we recognize personhood as moral status, the enhancement of moral status is ruled out.

Not so, according to Agar. He argues that moral status enhancement is compatible with the view that the moral status of persons is a threshold concept on the condition that moral status of persons is understood as a weak threshold. To make this point, Agar $(2014,162)$ draws a distinction between 1) a strong moral status threshold and 2) a weak moral status threshold. The first is a "point or region beyond which no improvement to the capacities relevant to moral status makes any difference to status." The second is a 
"point or region behind which moderate improvements to capacities relevant to moral status make no difference to status. Improvements of greater magnitude could make a difference to status." Buchanan's supposed impossibility of moral status enhancement follows from his assumption that the moral status of persons is a strong moral status threshold. However, if we posit a weak threshold in moral status, then Buchanan's obstacle seems to be removed.

How good is Agar's move? One may be tempted to see it just as a stipulation of the concept of a threshold, because it seems that all that Agar's supposed solution amounts to is saying that instead of Buchanan's strong threshold there is a weak one. Whether this complaint is justified depends on whether there is something in Buchanan's conception of moral status of persons that precludes such a stipulation. However, it is not easy to give a straightforward answer to this question as it involves controversial issues about the interpretation of the concept of moral status itself.

Buchanan in his discussion $(2011,218)$ makes it clear that there are at least two different models of thinking about moral status. According to socalled interest-based accounts, the moral status of a being depends upon what kind of interests it has. The more interests a being has, the higher its moral status. This view implies that there is a continuum of moral considerability without sharp divisions (See Figure 1$)^{6}$.

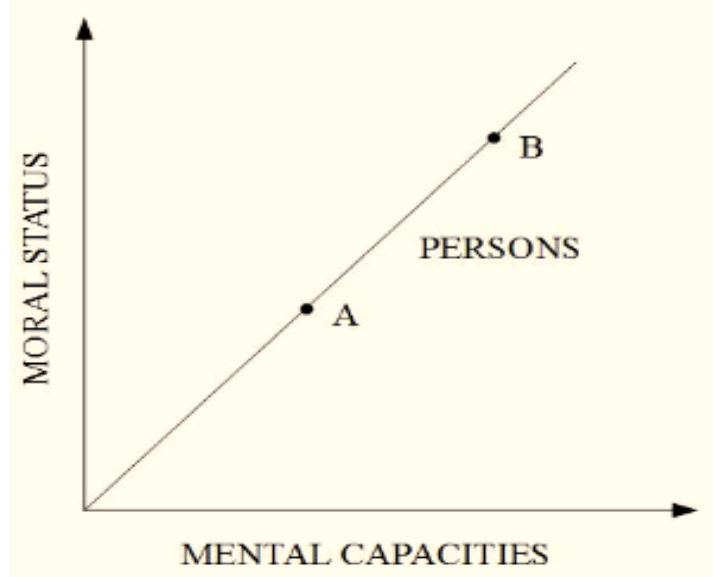

Figure 1: The interest-based account of moral status implies that the moral status of a creature is determined by its mental capacities. Persons are beings whose level of mental capacity is somewhere between $A$ and $B$. It is obvious that there is nothing in this model that precludes the existence of post-persons. Post-persons are located somewhere above $B$.

\footnotetext{
${ }^{6}$ Here and below my representation of the connection between metal capacities and moral status is inspired by Douglas (2013b).
} 
Buchanan claims that the interest-based account "seems to be a kind of debunking of the idea of different moral statuses" and that makes this model less plausible than the so called respect-based model which stems from Kantian moral philosophy. According to this account "all beings that possess certain capacities have an intrinsic moral worth that in some sense confers inviolability." But the moral worth in turn is grounded in "the capacity for practical rationality or for engaging in practices of mutual accountability" (mentioned in the passage quiet at the beginning of this chapter; see Figure 2).

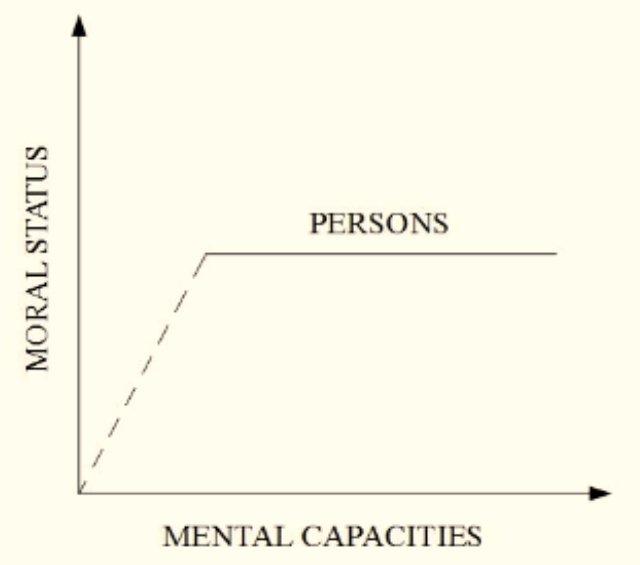

Figure 2: According to the respect-based model, moral status is a threshold concept. No improvement in mental capacities can enhance moral status as soon as a creature has reached a certain level of mental development.

There are several reasons why Buchanan prefers the respect-based model. For one thing, it better accommodates our common-sense intuition that nonhuman animals have lower moral status than persons. But most importantly:

It can explain why any being who clearly has the capacity in question is owed equal respect and hence why having the psychological and motivational characteristics that constitute the capacity to a higher degree does not confer higher moral status (2011, 218-219).

In other words, Buchanan claims that the respect-based account not only accommodates the Moral Equality Assumption, but can even explain it.

Now it is obvious that the interest-based model has no problem with allowing the possibility of beings whose moral status is higher than that of persons (if one accepts that the concept of a person has any relevance in this framework.) Agar on his part claims neutrality on the question of which model of moral status is more adequate and for the sake of the argument grants the existence of moral statuses $(2014,160-161)$. His contention is that even on this assumption there is no reason to rule out the possibility of moral status 
enhancement, because Buchanan's view is compatible with there being more than one threshold (see Figure 3) ${ }^{7}$.

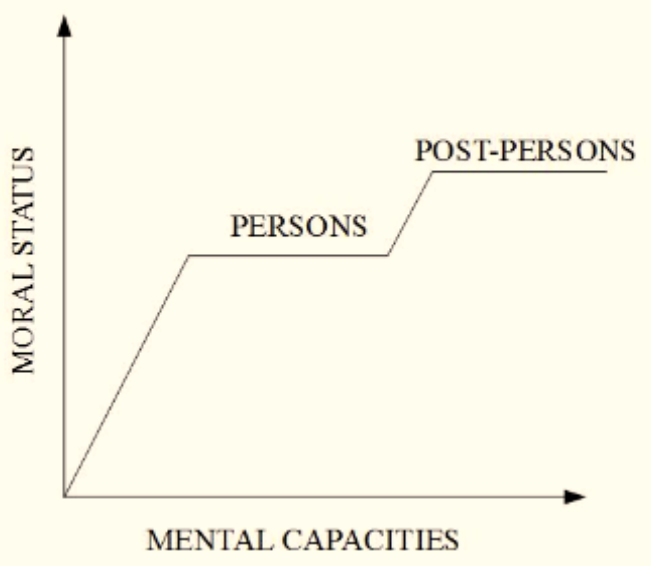

Figure 3: According to a weak moral status threshold moderate improvements in mental capacities make no difference to moral status, although improvements of certain magnitude could enhance moral status beyond that of persons.

By now it should be obvious that Agar is right if one of two following conditions is satisfied:

(1) The abilities (moral or non-moral) that define personhood are not threshold abilities, or

(2) There is/are some capacity/ies not related to personhood that a being may have, which enhance/enhances its moral status beyond that of mere persons.

Agar doesn't discuss the second possibility, so let me put it aside for a while (we will return to this issue later) and turn to the first. The idea here is that personhood is grounded in some capacities that the being in question has, and if those capacities are such that no improvement of them can change the being into a different kind of being, then these abilities are considered as threshold abilities. For example, if we, following Frankfurt (1971), would say that a being is a person if it has the capacity to have second order desires and beliefs, then it seems to be the case that no matter how this ability can be improved, it will not change the person into a different kind of being. As a consequence the capacity to have second order desires and beliefs should be considered a threshold ability. Can we say the same about Buchanan's proposed "capacity for practical rationality or for engaging in practices of mutual accountability" as the main characteristic of personhood? This is too complicated an issue to be addressed here. It seems that the main intuition

${ }^{7}$ Douglas (2013n) argues for the same conclusion. 
behind Buchanan's view that moral status is threshold concept is that capacity for practical rationality is also a threshold capacity, but whether this is really the case is a matter for a separate discussion.

At this point we can conclude that the problem of the logic of thresholds is too complicated to be solved by merely stipulating a new kind of threshold. On the other hand, if we take into account the two conditions that are mentioned above, it should also be admitted that Buchanan's account still leaves some room for the possibility of moral-status enhancement.

\subsection{Inviolability}

The problem of how to improve upon inviolability is somewhat similar (and related) to the problem of the logic of thresholds. It has already been noted that according to the respect-based model, persons have an "intrinsic moral worth that in some sense confers inviolability." This in turn implies that beings with higher moral status than mere persons deserve more respect than we owe to persons. But we have a problem-if persons already are inviolable, then what higher level of inviolability can be ascribed to post-persons? This problem-as in the previous case-is created by treating inviolability as a threshold concept ${ }^{8}$. To avoid the problem, Agar $(2014,163-164)$ follows McMahan (2009), who proposes to reject an absolutist reading of inviolability-a view according to which under no circumstances it could be right to sacrifice an inviolable being. McMahan appeals to a commonsense view that in some extreme cases it is justified to kill an innocent person as the only way to prevent the killing of a very large number of other innocents. This in turn implies that there is no absolute prohibition of sacrificing persons and as a consequence violability and inviolability comes in degrees. And if this is right, then there is no problem with the view that post-persons are relatively more inviolable than mere persons.

There are at least two things that can be said about Agar's strategy of avoiding the problem of inviolability. First, it seems that similarly as in dealing with the problem of thresholds, Agar again oscillates between respect-based and interest-based models of moral status. But even if we grant this, there is another, second, problem with the argument-it is invalid. From the observation that in some emergency cases it is justified to sacrifice an innocent person, it just doesn't follow that inviolability comes in degrees ${ }^{9}$.

\subsection{The expressibility problem}

Now let us turn to the problem that Agar $(2014,164-165)$ describes as "the most serious obstacle" to the possibility of moral status enhancement. If we entertain the possibility of creating post-persons, we should be able to describe what kind of beings post-persons are. However, as soon as we try to

${ }^{8}$ As Buchanan explicitly does $(2011,221)$.

${ }^{9}$ See also Buchanan $(2011,222)$. 
do it we find it impossible. Buchanan in this failure sees a reason to doubt the plausibility of the very concept $(2011,217)$. He claims that:

From the perspective of the respect-based view, it is hard to imagine what a higher threshold-one that required a higher moral status-would be like. It does not seem plausible to say that it would consist simply of higher levels of the same characteristics that now constitute the threshold the respect based view employs. In the absence of an account of what the higher threshold would be like, the claim that there could be beings at a higher threshold who would have a higher moral status is not convincing $(2011,220)$.

At the same time Buchanan admits that the impossibility to imagine higher moral status by itself doesn't solve the issue, as failure of imagination and conceptual incoherence are two different things $(2011,217)$. But still, he asks: "How can we explore the moral implications of what we cannot imagine?" Now it seems that all hangs on whether it is possible to describe higher moral statuses. Buchanan correctly points out that the strategy to augment the capacities that account for personhood is a non-starter, because instead of post-persons we will get perfected mere persons. Agar $(2014,158-159)$ draws a useful distinction between moral disposition enhancement and moral status enhancement. The aim of moral disposition enhancement is to increase the moral value of an agent's character, e.g., to improve his or her abilities to empathize, resist different biases etc. The aim of moral status enhancement, on the other hand, is to increase the degree of respect that is owed to a being. To try to explain higher moral statuses by reference to more enhanced moral characteristics is to commit the common mistake of confusing moral status enhancement with moral disposition enhancement ${ }^{10}$. Is there any other strategy that would avoid this fallacy? Agar thinks that there is, but before we go to the solution it is important to get clear what, according to Agar, is the main source of the problem.

He speculates $(2014,175)$ that the reason we cannot grasp the criteria for post-personhood is because they are constituted by abilities that are cognitive: "The fact that criteria for post-personhood are cognitive is a barrier to mere person's powers of expression and imagination." The assumption here seems to be that we must think about our relation to personhood in the same way as we imagine, say, a dog's relation to a human person. As the criteria for personhood are constituted by the abilities that are cognitive, the dog is as clueless about persons as we are about post-persons. And it is obvious that from the dog's cluelesness about persons it doesn't follow that persons don't exist.

10 Agar (2014, 167-174) criticizes DeGrazia (2012), McMahan (2009) and Douglas (2013b) for too much relying on the link between disposition and moral status enhancement. 
So the question now is-how to overcome our cognitive barrier? Agar rather ingeniously suggests that this limitation can be overcome by deferring to beings who are able to grasp the criteria for post-personhood. This should be viewed in a similar way as our deference to other people whose skills and imaginative powers exceed our own. If we believe in the sincerity and expertise of physicist or mathematician, then we rely on what they say to us, even if sometimes we find it hard to grasp properly. Provided that postpersons would lack our cognitive limitations, they would be able to know all morally relevant facts known by persons and also those that persons are ignorant about.

Thus Agar has prepared the ground for what he calls a "moderately strong inductive argument" for the existence of criteria for post-personhood.

\subsection{The moderately strong argument}

To arrive at the desired conclusion, Agar $(2014,178)$ advances two claims: $\mathrm{He}$ proposes, first, that the capacities that constitute moral status have no upper limit, and second, that it is quite likely that beings with enhanced cognitive powers would be able to recognize a moral status that is higher than that of persons. If we grant this, then available evidence should incline us to accept this hypothesis:

There is some degree of improvement of capacities constitutive of status that cognitively superior beings would recognize as creating a moral status higher than personhood $(2014,179)$.

Agar considers this conclusion moderately strong because it is derived by extrapolating from the three recognized moral statuses $(2014,180)$ :

1) Moral status category 1 (The zero moral status possessed by rocks);

2) Moral status category 2 (The moral status possessed by sentient nonpersons);

3) Moral status category 3 (The moral status possessed by persons);

The existence of those statuses makes it reasonable to believe in the existence of:

4) Moral status category 4 (the moral status possessed by post-persons).

As imaginative as it is, the argument has some problems. To begin with, it relies on the controversial assumption that there is no upper limit to the cognitive capacities that determine the moral status of persons. It has already been noted that this largely depends on which account is preferred by a particular author as the most plausible account of the moral status of persons. The capacity that serves this role in Agar's argument is practical reasoning which, he argues, is a capacity that can be improved infinitely. However, at least on one account this doesn't ring true. If to be an ideal or perfect practical reasoner means to be able to make the best decisions in particular areas of 
expertise from the point of view of a particular set of values, then it doesn't look like an ability that can be always improved. Of course, things get more complicated as soon as we widen the area about which we have to make decisions. Compare a situation in which a physician has to administer certain drug to a patient with a certain well studied condition, with a situation in which I have to decide whether to move to city X or to city $\mathrm{Y}$. The latter case is more complicated because more values are involved and a smaller number of relevant facts is available. However, it is far from clear whether the ability to know all the relevant facts and greater clarity about values would necessarily make me a better practical reasoner, although no doubt I would be able to make better decisions.

Next, after a closer look the argument doesn't seem to be moderately strong. Agar claims that the existence of moral status category (4) can be extrapolated from three observed moral statuses. However, if we look closer to the way in which the moral status categories are related, this claim seems unjustified. Sentient non-persons have higher moral status than rocks due to their sentience. However, persons supposedly have higher moral status than sentient-non persons not because they have more of what sentient nonpersons have, but due to capacities of completely different kind, such as the ability to engage in practices of mutual accountability or the capacity to have second order desires and beliefs, etc. Now the conclusion that post-persons have higher moral status because they have more of something that constitutes personhood does not seem very well supported (cf. Hauskeller $2013,76)$. In fact, from this point of view the argument rather supports the conclusion that post-persons have higher moral status in virtue of having some completely new kind of ability that mere persons lack (cf. Wasserman 2013, 79).

As a consequence I find Agar's argument unconvincing. No doubt, one is still free to claim that in spite of all the possible flaws of Agar's account, the possibility of moral status enhancement still cannot be ruled out. This is true, but this possibility looks less interesting now. In the next chapter I will try to give some additional reasons why this should be so.

\section{What Can We Learn from Post-Persons?}

In the previous section I mainly explored Agar's well-argued account of the possibility of moral status enhancement and just occasionally commented on some possible problems with some of the steps in his reasoning. But there are larger issues that can be raised with regard to the overall framework of the present discussion. I presume that some conclusions drawn by Agar may seem rather strange to many people. My contention is that this strangeness is a consequence of some basic and implausible assumptions made by Agar and some other authors. 


\subsection{Expressibility again}

Let us return to the problem of expressibility, as I believe this will help us to see one problematic feature of Agar's account. Agar defends the view that there are higher moral statuses than those that we ascribe to persons (see Figure 3). But remember that due to our lack of cognitive power we are not able to grasp moral statuses higher than ours. In other words, Figure 3 shows us the situation as it appears from the point of view of the post-persons. From our perspective, things look rather as they are depicted in Figure 4.

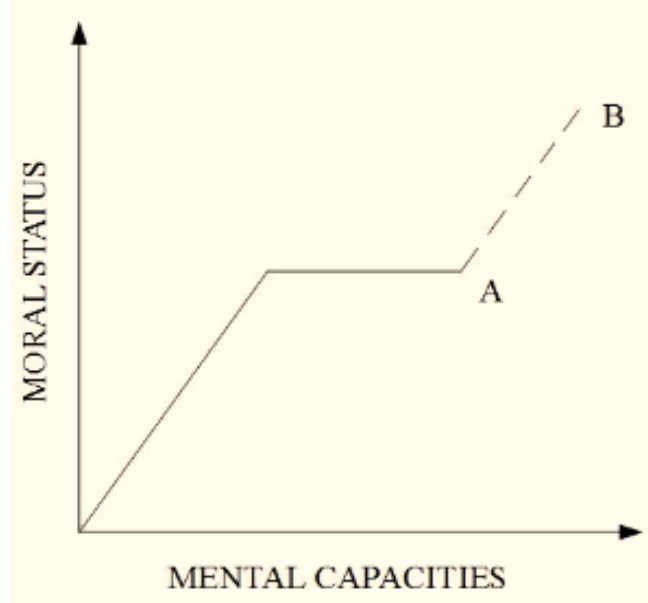

Figure 4: Higher moral statuses as they are seen from our limited perspective. The line AB depicts the spectrum where the higher moral status is located, but we are not able to grasp it.

Figure 4 is similar to Figure 2. The main difference between them is the addition of the dotted line AB. Somewhere on this line should be a new threshold which marks the location of post-persons. However, as our cognitive capacities are limited we are not able to grasp it. Whatever there is on the $A B$ line, we are blind to it. Figure 3 describes reality, while Figure 4 represents our phenomenology. Or so we are told. Great! But provided those conditions, how can we engage with them ethically? If they are as Agar describes them, then they do not seem to be visible on our moral radars. Or if they are there, then they don't differ from other persons. The problem here is that according to Agar's account, the enhanced moral status of post-persons is epistemically and ethically sealed from us. Agar tries to solve this problem by arguing that we should defer to sincere post-persons, as students rely on their more knowledgeable instructors. However, I am afraid that this analogy does not hold the water, because there is an important difference between persons and post-persons on the one hand and students and their instructors on the other. In the student-instructor case, the student is in principle able to grasp what is said by the instructor or at least it is clear how the student can share the world inhabited by the instructor. Nothing like that holds in the case of our relation 
to post-persons. We are asked to defer to the view of sincere, cognitively superior beings; however, it is far from clear how we would be able to recognize them.

The main problem here seems to be that Agar works under the assumption that in some relevant respect there is no big difference between the scientific and the ethical; and as a consequence he dismisses the role of phenomenology in shaping our ethical attitudes. ${ }^{11}$ Agar describes post-persons as a sort of physical substance that can be discovered by us, provided that we use the proper tools:

Moral statuses higher than personhood can be viewed as analogous to objects including space-time singularities whose existence we can infer without our being able to directly observe them $(2014,158)$.

Described in such a way, post-persons seem like Epicurean gods. They are great, but hardly make any moral or any other difference for us.

\subsection{Morally sensitive Martians}

Another characteristic feature of Agar's (and not only his) account is a noticeable lack of human perspective. Instead of this we are offered a view on things from the point of view of the universe (cf. Willliams 2006). For example, in his brilliant paper "Human enhancement and supra-personal moral status" T. Douglass makes the following comment about Buchanan's claim on moral status of persons as a threshold concept:

It would be a surprising good fortune for humanity if the threshold form maximum moral status lay just below the level of mental capacity typical of ordinary adult humans $(2013 \mathrm{~b}, 481)$.

Douglas implies that it is not only the case that moral statuses somehow exist out there for anybody to discover, but that they have the same moral importance across the entire Universe. In a rather similar manner, Savulescu $(2009,235)$ with approval quotes McMahan $(2002,227)$, who claims that:

We owe to them [animals] whatever kind of treatment we believe the severely retarded would be owed in virtue of their intrinsic natures by morally sensitive Martians (emphasis added).

We may of course wonder why those morally sensitive Martians sound quite similar to Peter Singer, McMahan himself or some other utilitarians. In a rather Humean fashion we may ask which of the two hypotheses has the higher probability of being true:

11 In his argument Agar constantly takes moral reasoning to be similar to mathematical reasoning (see 2014, 177, 178). The issue of the relationship between science and ethics is too large to address here. The account I find myself in agreement with is that of Williams (1985, Ch. 8). 
1) McMahan and others have discovered some moral features that are relevant even to Martians;

2) McMahan's view that sentience and personhood matter even to Martians can be explained in some other way, for example as a bias toward features that we humans find morally important.

If matters are viewed in this way, then the second hypothesis seems more probable than the first. I would speculate that this sort of bias is at work when we tend to imagine animals as a sort of handicapped humans (notice, that McMahan's sensitive Martians don't see the difference) or when we try to imagine post-persons as surpassing us by having the same capacities that makes us persons but just in considerably higher degree. Of course, we cannot be sure that this is wrong. It is just highly improbable. This observation implies a sort of irony because one of the most important features of utilitarian ethics according to its proponents is the ability to overcome our biased human outlook and enable as to widen our moral circle. Now it seems that there is a sort of human bias at the very roots of the utilitarian outlook.

\section{Conclusion}

In spite of the objections that one can raise against Agar's arguments for the possibility of moral status enhancement, there are no conclusive reasons that would rule out the existence of post-persons. However, if post-persons are as they are described in Agar's account, their possible existence seems to be less interesting than one might think. There are at least two reasons for this. First, Agar ignores the importance of phenomenology in shaping our moral attitudes. Secondly, his account seems to be biased as it ascribes universal importance to the features that we as humans happen to find morally relevant from our local human perspective. Thus by constructing the account of postpersons we don't correct our ethical myopia, but rather express it.

\section{Acknowledgments}

I would like to thank the anonymous reviewer for the useful comments which helped me to improve the quality of this paper. Also, I would like to thank Simon Jenkins for language editing of this manuscript.

\section{References}

Agar, N. 2013. "Why Is It Possible to Enhance Moral Status and Why Doing So Is Wrong?." Journal of Medical Ethics 39: 67-74. 
Agar, N. 2014. Truly Human Enhancement: A Philosophical Defense of Limits. Cambridge, Mass.: The MIT Press.

Annas, G. 2002. "Cell Division". Boston Globe. Retrieved from: http://www.geneticsandsociety.org/article.php?id=164

Fukuyama, F. 2002. Our Posthuman Future. Consequences of the Biotechnology Revolution. London: Profile Books.

Buchanan, A. 2009. "Moral Status and Human Enhancement." Philosophy \& Public Affairs 37(4): 346-381.

Buchanan, A. 2011. Beyond Humanity. Oxford: Oxford University Press.

DeGrazia, D. 2012. "Genetic Enhancement, Post-Persons and Moral Status: A Reply to Buchanan." Journal of Medical Ethics 38: 135-139.

Douglas, T. 2013a. "The Harms of Status Enhancement Could Be Compensated Or Outweighed: A Response to Agar." Journal of Medical Ethics 39: 7576.

Douglas, T. 2013b. "Human Enhancement and Supra-Personal Moral Status." Philosophical Studies 162: 473-497.

Frankfurt, H. 1971. "Freedom of the Will and the Concept of a Person." Journal of Philosophy 68: 5-20.

Hauskeller, M. 2013. "The Moral Status of Post-Persons". Journal of Medical Ethics 39: 76-77.

McMahan, J. 2002. The Ethics of Killing. Oxford: Oxford University Press.

McMahan, J. 2009. "Cognitive Disability and Cognitive Enhancement." Metaphilosophy 40: 582-605.

Persson, I. 2013. "Is Agar Biased Against «Post-Persons»? Journal of Medical Ethics 39: 77-78.

Savulescu, J. 2009. "The Human Prejudice and the Moral Status of Enhanced Beings: What Do We Owe the Gods?" In J. Savulescu \& N. Bostrom (eds.), Human Enhancement. Oxford: Oxford University Press: 211-247.

Sparrow, J. R. 2013. "The Perils of Post-Persons." Journal of Medical Ethics 39: 80-81.

Wasserman, D. 2013. "Devoured by Our Own Children: The Possibility and Peril of Moral Status Enhancement." Journal of Medical Ethics 39: 7879.

Williams, B. 1985. Ethics and the Limits of Philosophy. Cambridge: Harvard University Press.

Williams, B. 2006. "The Human Prejudice." In idem, Philosophy As a Humanistic Discipline..Princeton: Princeton University Press: 135-152.

Bühler, Ch. 1929. Das Seelenleben des Jugendlichen.Versuch einer Analyse und Theorie der psychischen Pubertät. Jena: Fischer Verlag.

Garz, D. 1999. "»Also die Annahme, daß die Welt gerecht ist, das wäre sehr irrational«. Urteil, Handeln und die Moral des Alltagslebens". In D. Garz, F. Oser, \& W. Althof (Hg.), Moralisches Urteil und Handeln. Hamburg: Reclam: 377-406. 
Oevermann, U. 2001. "Das Verstehen des Fremden als Scheideweg hermeneutischer Methoden in den Erfahrungswissenschaften". Zeitschrift für Qualitative Bildungs-, Beratungs- und Sozialforschung 1: 21-64. 


\title{
Ivars Neiders (Rīga)
}

\section{Can There Be Post-Persons and What We Can Learn From Considering Their Possibility?}

\begin{abstract}
Many prominent bioethicists have recently raised the question of the possibility of moral status enhancement. In this paper I discuss the arguments advanced by Nicholas Agar for the possible existence of the postpersons. I argue that in spite of the many limitations and shortcomings of Agar's account, there are no conclusive reasons to rule out the possibility of moral status enhancement. However, if post-persons are as they are described by Agar, the fact of their possibility is less interesting and ethically relevant than it might seem. Most importantly, the account of post-persons given by Agar is rather an outcome of some implausible assumptions. I propose that Agar conflates the ethical with the scientific and dismisses the importance of phenomenology in framing our ethical outlook. Also, he seems to follow the assumption made by many utilitarian ethicists that such features as sentience and cognitive capacities have some universal relevance. This accounts for the delusion that we can view our moral attitudes from the point of view of the Universe.
\end{abstract}

Keywords: Enhancement, moral status, persons, post-persons

Ethics in Progress (ISSN 2084-9257). Vol. 6 (2015). No. 1, pp. 56-71.

doi: 10.14746/eip.2015.1.6 